\title{
Lessons from technology development for energy and sustainability
}

M.J. Kelly, Electrical Engineering Division, Department of Engineering, University of Cambridge, Cambridge CB3 OFA, UK

Address all correspondence to M.J. Kelly at mjk1@cam.ac.uk

(Received 5 January 2015; accepted 16 November 2015)

\section{ABSTRACT}

\section{There are lessons from recent history of technology introductions which should not be forgotten when considering alternative energy technologies for carbon dioxide emission reductions.}

The growth of the ecological footprint of a human population about to increase from 7B now to 9B in 2050 raises serious concerns about how to live both more efficiently and with less permanent impacts on the finite world. One present focus is the future of our climate, where the level of concern has prompted actions across the world in mitigation of the emissions of $\mathrm{CO}_{2}$. An examination of successful and failed introductions of technology over the last 200 years generates several lessons that should be kept in mind as we proceed to $80 \%$ decarbonize the world economy by 2050. I will argue that all the actions taken together until now to reduce our emissions of carbon dioxide will not achieve a serious reduction, and in some cases, they will actually make matters worse. In practice, the scale and the different specific engineering challenges of the decarbonization project are without precedent in human history. This means that any new technology introductions need to be able to meet the huge implied capabilities. An altogether more sophisticated public debate is urgently needed on appropriate actions that (i) considers the full range of threats to humanity, and (ii) weighs more carefully both the upsides and downsides of taking any action, and of not taking that action.

Keywords: energy generation; environment; government policy and funding; environmentally benign

\section{DISCUSSION POINTS}

- Only fossil fuels and nuclear fuels have the ability to power megacities in 2050, when over half of the then 9B people will live in them.

- As the more severe predictions of climate change over the last 25 years are simply not happening, it makes no sense to deploy the more costly options for renewable energy.

- Abandoned infrastructure projects (such as derelict wind and solar farms in the Mojave desert) remain to have their progenitors mocked for decades.

\section{Introduction}

The present debate concerning the finite capacity of the earth to support humanity can be traced back to the Rev Thomas Robert Malthus FRS ${ }^{1}$ who in his 1798 paper "An Essay on the Principle of Population" stated "The power of population is so superior to the power in the earth to produce subsistence for man, that premature death must in some shape or other visit the human race." He started a widespread debate at the time as recorded by Mayhew. ${ }^{2}$ Malthus prompted a response, with which I have considerable sympathy, from the 1 st Baron Macaulay FRS in 1830: "On what principle is it that, when we look we see nothing but improvement behind us, we are to expect nothing but deterioration before us?" Just as Malthus spoke, steam powered machines were introduced to aid agricultural harvesting and there was no mass starvation across Europe (with the exception of the Irish Potato famine, which could have been alleviated with more enlightened aid policies). Since then there have been successive warnings about coal exhaustion by William Stanley Jevons FRS in $1868,{ }^{4}$ and by the Club of Rome ${ }^{5}$ who in 1970 predicted the exhaustion of a number of minerals by the year 2000, but only helium is actually in short supply. There have been regular warnings about peak oil (even before 1900!), with one of the most recent work by Murray and King in $2006 .^{6}$ The Malthusian debate has never receded totally, but millennial thinking has brought it back into prominence in modern times.

This quick review of the history of the prophets of doom shows a record of failure. The now known fossil fuel reserves will last for over 40 years. ${ }^{7}$ Fracking, a relatively old technology, when applied to shale beds is providing access to large fossil fuel 
reserves of both gas and oil, and the widespread fields of methane hydrates on the sea-bed are just the latest in the growing finds of fossil fuels. Indeed we have used less than $10 \%$ of the now known fossil fuel reserves (conventional and unconventional) since the start of the industrial revolution. ${ }^{8}$ The rational response to yet more predictions of doom is to start with a deep scepticism as history is not on their side. In response, the neo-Malthusians have to be increasingly dramatic to capture and hold attention in the public debate. Someday a neo-Malthusian may be proved right, but not yet, and maybe never, especially if some galactic event intervenes. ${ }^{9}$ I have stressed above the role of individuals in the Royal Society taking a leading role in the debates: it continues to this day with individuals aligned on both sides. ${ }^{10}$ The one change from history is that a bylaw of the Society that stood for most of its history has been overturned in recent decades. Whereas once "...it is an established rule of the Society, to which they will always adhere, never to give their opinion as a body upon any subject either of Nature or of Art, that comes before them", 11 now the Royal Society plays an active role in the debate, coming at it from only one side, without adequate acknowledgement of the lack of unanimity within the fellowship. ${ }^{12}$ Most of the engineering Fellows I have consulted have some reservations about the current stand, reservations that are reflected here. One should be able to look to the academies worldwide for an open, balanced, and full discussion of these matters, with engineering-level integrity when contemplating what actions to take: in practice, the level of 'post-normal science' (where the 'facts are uncertain, values in dispute, stakes high, and decisions urgent' ${ }^{13}$ ) gets in the way. There is no such thing as post-normal engineering. There is an abundance of reports focussing on the energy needs of humanity and the sustainability of mass action, but relatively little acknowledgement of the upsides of present cities as a way for allowing large populations to live in some comfort.

In this review, I want to concentrate on the measures taken to reduce the global emissions of carbon dioxide, and how the lessons from recent history of technology introductions can inform the decarbonization project. I want to review the last 20 years in particular and see what this portends for the next 40 years which will take us beyond 2050 , which is the pivotal date in the public discourse. A Royal Commission into Environmental Pollution in 2000 advocated a $60 \%$ reduction of carbon dioxide emissions for the UK by $2050 .{ }^{14}$ The date was fixed by the response to the enquiry as to when energy from nuclear fusion might supply $10 \%$ of the world's energy needs. The answer was not before 2050 , and we will need to get there without it. The revision from $60 \%$ to $80 \%$ reduction came from concern that developed countries should make allowances for developing countries using fossil fuel to escape poverty, i.e., they can take the same route as developed countries did to their relative affluence. We have had over 20 years since the first Earth Summit in Rio de Janeiro in 1992, where 1990 emissions of carbon dioxide were agreed upon as the benchmark for reductions. Before discussing specific technologies, I want to establish the scale of the challenge in engineering, technology, and project delivery terms: this does include economics, societal attitudes, and the public discourse. I also discuss some engineering fundamentals. I will then summarize the many lessons of technology introductions, the preparation for other global challenges, and finally discuss a realistic way forward.

The UK is unique in having passed into statute the Climate Change Act of 2008 with a Committee on Climate Change tasked to oversee the delivery of an $\mathbf{8 0 \%}$ decarbonized economy by $2050 .{ }^{15}$ Practical engineering experience of complex engineering projects has been notably absent in the delivery debate.

\section{Decarbonizing the world economy}

The Intergovernmental Panel on Climate Change's (IPCG) fifth assessment report, issued in 2014, asserts that it is more confident than ever that mankind is responsible for over half the global warming since 1950 because of our emissions of carbon dioxide principally from the burning of fossil fuels. ${ }^{16}$ The strong and critical debate about the strength and integrity of that assertion is not our primary concern here, and I start by accepting the IPCC's Fifth Assessment Report at face value, although I shall return to this towards the end. I am concerned that what is done in the name of decarbonization should leave the world in a better place. I am sure that what has been done so far in the name of decarbonization is set to fail comprehensively in meeting its avowed target, and that a new debate is needed. If our emissions of carbon dioxide are causing the world to warm and lead into possibly difficult times in the future, it is important also to establish the upsides of such emission. Peter Allitt quotes: "The rising carbon dioxide footprint may be troublesome, but it is a side effect of the creation of immense benefits." 17

\section{Scale}

It is important to note the scale of the perceived problem. The entire history of modern civilization that started with the first industrial revolution has been enabled by the burning of fossil fuels. Our mobility, our health and lifestyles, our diet and its variety, our education system, particularly at the higher level, and our high culture would be quite impossible without fossil fuels, which have provided over $90 \%$ of the energy consumed on the earth since 1800. Today, geothermal, hydro- and nuclear power, together with the historic biofuels of wood and straw, account for about $15 \%$ of our energy use. ${ }^{18}$ Even though it is 40 years since the first oil shocks kick-started the modern renewable energy developments (wind, solar, and cultivated biomass), we still get rather less than $1 \%$ of our world energy from these sources. Indeed the rate at which fossil fuels are growing is seven times that at which the low carbon energies are growing, as the ratio of fossil fuel energy used to total energy used has remained unchanged since 1990 at $85 \% .{ }^{19}$ The call to decarbonize the global economy by $80 \%$ by 2050 can now only be described as glib in my opinion, as the underlying analysis shows it is only possible if we wish to see large parts of the population die from starvation, destitution or violence in the absence of enough low-carbon energy to sustain society.

A further insight into the scale of present day energy consumption is as follows. In Europe, today, we use about 6-7 times 
as much energy per person per day as was used in 1800, and there are seven times as many people on earth now as compared with then. ${ }^{18}$ The energy of 1800 was expended on heating and lighting one room in a house and producing hot water used in that same room, and on the purchase of local produce and manufactures. By examining the breakdown of today's energy usage in the UK and Europe ${ }^{20}$ this energy use persists today, but with lighting and central heating of whole buildings. In addition, Europeans today use as much energy per person per day on private motoring as they used in total in 1800. They use an equal amount on mobility through public transport: trains, ships, and aeroplanes. Three times the personal consumption of 1800 is used in the manufacture and logistics of things we consume or use, such as food or manufactured goods.

The full conundrum facing humanity can be seen with reference to Fig. 1(a), which shows that the global demand for energy has increased by $40 \%$ over the last 20 years, with over $85 \%$ provided by fossil fuels. ${ }^{21}$ The number of people described by the World Bank as being middle class doubled from 1.5B to $3 \mathrm{~B}$ over that period [Fig. 1(b)]. ${ }^{22}$ The definition of middle class is minimal-such people live in a home with electricity and running water, having a refrigerator for food storage and access to modern communications to warn of any dangers, with no mention of car ownership or access to aviation, the province of the rich. Indeed the whole graph could be explained by this growth in the middle class if such people use 3.5 times as much energy as those described as poor, a figure not inconsistent with the findings of MacKay. ${ }^{20}$ Over the next 20 years, the World Bank estimates that the middle class will rise from $3 \mathrm{~B}$ to $5 \mathrm{~B}$, on the basis of which $\mathrm{BP}$ estimates a further increase in global energy demand of $40 \%$ still to be met in the main by fossil fuels. The graph in Fig. 1(a) is on the wrong scale to show that the total installed renewable energy capacity as of today is equal to the combined capacity of the nuclear power plants shut down in Japan and scheduled to close in Germany, making the challenge of carbon free energy impossible to meet.

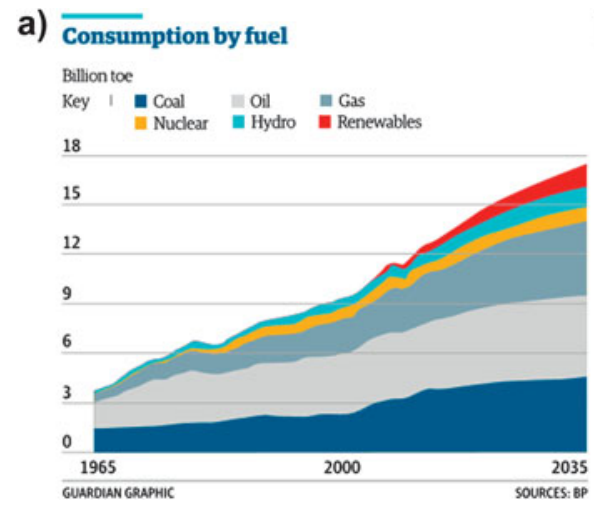

\section{Energy return on investment (EROI)}

The debate over decarbonization has focussed on technical feasibility and economics. There is one emerging measure that comes closely back to the engineering and the thermodynamics of energy production. The energy return on (energy) investment is a measure of the useful energy produced by a particular power plant divided by the energy needed to build, operate, maintain, and decommission the plant. This is a concept that owes its origin to animal ecology: a cheetah must get more energy from consuming his prey than expended on catching it, otherwise it will die. If the animal is to breed and nurture the next generation then the ratio of energy obtained from energy expended has to be higher, depending on the details of energy expenditure on these other activities. Weißbach et al. ${ }^{23}$ have analysed the EROI for a number of forms of energy production and their principal conclusion is that nuclear, hydro-, and gasand coal-fired power stations have an EROI that is much greater than wind, solar photovoltaic (PV), concentrated solar power in a desert or cultivated biomass: see Fig. 2. In human terms, with an EROI of 1, we can mine fuel and look at it-we have no energy left over. To get a society that can feed itself and provide a basic educational system we need an EROI of our base-load fuel to be in excess of 5, and for a society with international travel and high culture we need EROI greater than 10 . The new renewable energies do not reach this last level when the extra energy costs of overcoming intermittency are added in. In energy terms the current generation of renewable energy technologies alone will not enable a civilized modern society to continue!

This has been reinforced by a very careful analysis of the Spanish Solar Photovoltaic revolution during 2006-2009. Prieto and Hall (2013) ${ }^{24}$ point out that, because of the legislation associated with solar subsidies in Spain, the data are complete, clean, and unambiguous. They proceed to calculate the EROI by adding up all the costs associated with renting and clearing the land for the solar panels, making the solar panels, getting them to the site, installing and connecting them to the grid, and providing for their maintenance (panels washed four times a

b)

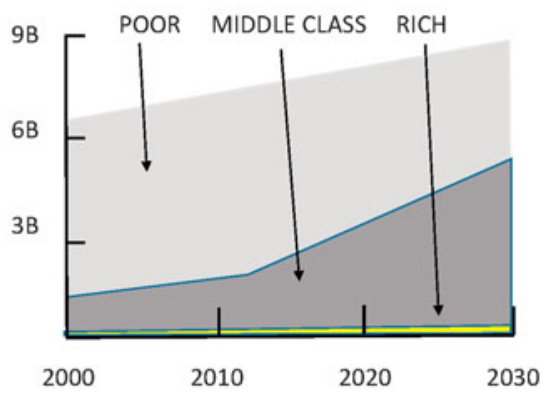

Figure 1. (a) The $40 \%$ growth of global energy consumption since 1995 and the projected $40 \%$ growth until 2035 , with most of the growth between 1995 and 2035 being provided by fossil fuels, ${ }^{21}$ and (b) the cause of this growth is the rise in the number of people living in the 'middle class' as described in the text. ${ }^{22}$ 


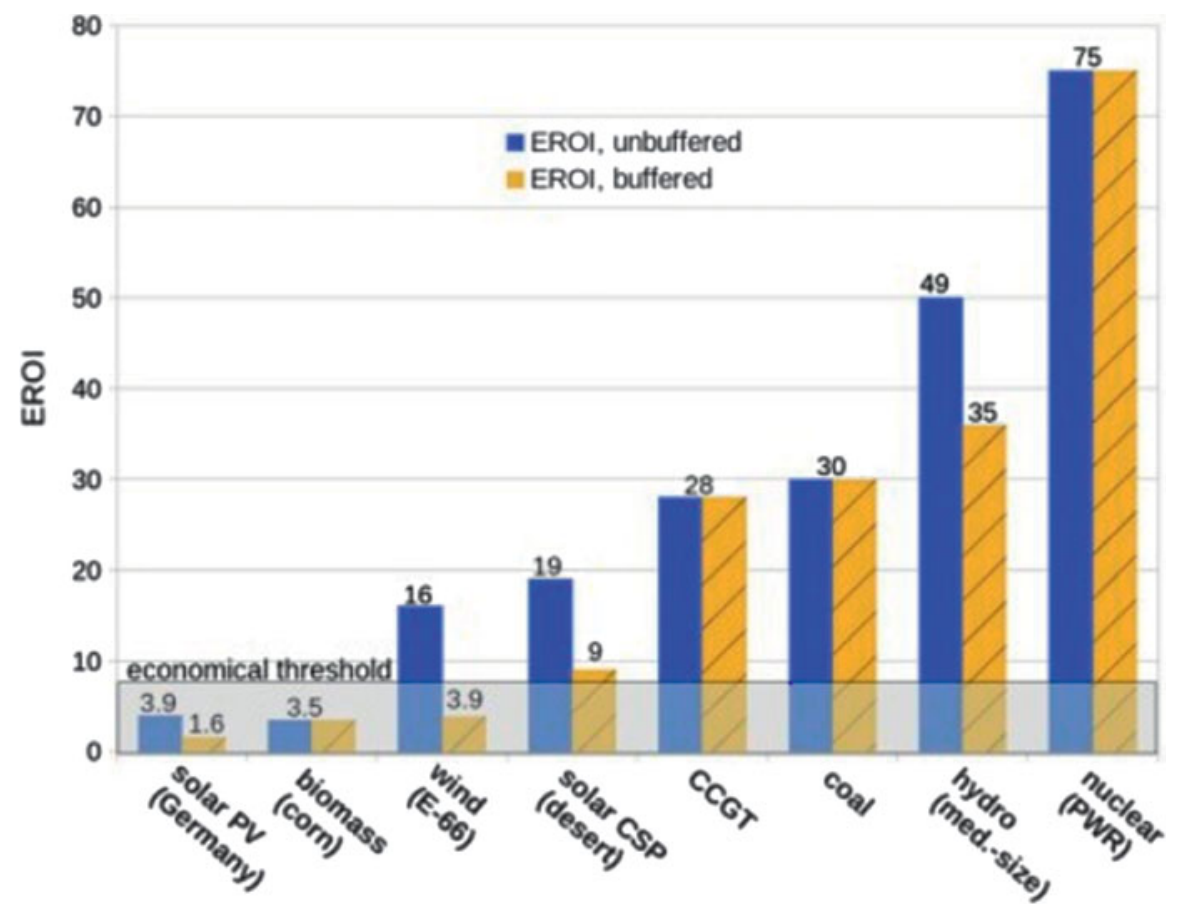

Figure 2. The energy return on energy invested for various forms of energy generation with the threshold for supporting a modern economy indicated across the bottom. ${ }^{23}$ The advantages of fossil fuels and nuclear energy are very clear. Reprinted from Ref. 23, with permission from Elsevier.

year and six times if within $200 \mathrm{~m}$ of dirt tracks), and ensuring the security by surveillance for solar farms. They use the ratio of the total Spanish energy usage to the Spanish gross domestic product (GDP) to convert this cost into the energy in, i.e. that energy expended in getting the solar panels to produce energy. By taking the metered use of electricity over the initial years and extrapolating over a 25 years lifetime, they get the energy out. They calculate a ratio of EROI $=2.45$, and draw the conclusion that without the substantial use of fossil fuel or nuclear energy, Spanish society will be much more primitive in 2050 than it is today. Note that if the solar panels were free the EROI rises to only about 4, still far too low to provide for a modern civilization.

It is often said that a new large-scale battery technology would transform the role of renewable energy, but in Fig. 2 we see the potential limitations. The reference to buffered energy systems based on a renewable energy source shows the degradation in terms of energy return on investment, when additional batteries are used to provide access to the renewable energy on demand, or as baseload. This feature is rarely described in debates on large scale energy storage.

\section{Feasibility}

Although the mantra 'think global, act local' is called upon to justify the local efforts on carbon dioxide emission reductions, there is not enough analysis of the impact of the total of all the local actions. The problem is represented by the following challenge. Suppose the world unites and agrees to provide $\$ 1$ pa for ten years to mitigate future adverse climate change.
What is the best strategy for spending that money for the reason given, namely to mitigate future climate change, and what will we be able to measure as the outcome of such an investment? The answer is that no-one knows the latter now, or will ever know on the 2050 timescale. A crude calculation suggests that such a sum would allow the capture of all the $\mathrm{CO}_{2}$ from coal fired power stations over the next year, reducing global $\mathrm{CO}_{2}$ emissions by about $40 \%$. But what difference would that actually make to the future climate, and would we be able to measure that difference as being attributable to the $\$ 1$ Tpa spent, and so even begin to assess the potential value-for-money of the investment? What if the sun goes cool, or we have a spate of major volcanic eruptions: would we be able to isolate the contribution from the reduced $\mathrm{CO}_{2}$ emissions? No. It is sober to compare the sheer scale of this undertaking in view of the total uncertainty in the outcome. It is a current act of faith that investments in green energy projects are intrinsically good, but this belief will be challenged from several directions in section "Generic lessons learned from introducing new technologies applied to decarbonization" of this paper. When one could distribute the same money and give the poorest $1 \mathrm{~B}$ on earth $\$ 10 \mathrm{Kpa}$ each (assuming good governance, which is a large assumption), the likely measureable impact is very much clearer to anticipate and attribute and measure subsequently. The only attempt so far to consider a spent getting to $\$ 1$ pa by 2030 on clean energy 25 focuses entirely on the financial instruments, and has nothing to say on candidate engineering projects and so no attempt to rank them in terms of efficacy, value for money, or any other outcomes criterion. 


\section{Fuel energy density}

Another feature of scale needed to understand the present attempt to avoid the use of fossil fuel is the energy density of the fuel itself. Today's fossil fuels are the result of past photosynthesis and the densification of the resulting energy over millions of years. One liter of petrol when burned releases chemical energy of most bonds as heat that is equivalent to gravitational energy of raising $36 \mathrm{~m}^{3}$ of water by $100 \mathrm{~m}$ in hydroelectricity terms. The actual energy density of fossil fuel is over a million times greater than gravity energy density. In turn nuclear fuels are a million times more energy dense than fossil fuels. ${ }^{26,27}$ See Table 1.

It would take all the $4000 \mathrm{~km}^{2}$ of the Fen Country in the East of England, today producing foodstuffs, to produce as much energy from growing and burning miscanthus grass as a biofuel to generate the 1.3-1.5 GW continuous power provided by Sizewell $\mathrm{B}$, a nuclear plant that fits comfortably into $0.1 \mathrm{~km}^{2}$. This is a ratio of over $10^{4}: 1$ in terms of the efficiency of land use for energy production. The net average energy density per square meter for current biomass, solar, and wind energy systems are all within a factor of about 20 of each other at $1-20 \mathrm{~W} / \mathrm{m}^{2}$, and this is simply nothing in comparison with the factor of tens of thousands just described. ${ }^{20}$ This means that the first generation of renewable energies all suffer from the intrinsic diluteness of solar energy incident on the surface of the earth, coupled with the low efficiency with which it is converted into a continuous useful energy supply. Modifications to the designs of wind turbine blades, solar panels, or growth rates of biofuel materials (including algae) result in increases in efficiency that is measured in (say) $10 \mathrm{~s}$ of percent: this is simply nothing compared with the millions of percent implied by fossil fuel energy density. These vast ratios are reflected in the size, costs, and safety issues associated with different sources of energy,

Table 1. Energy densities of different fuels.

\begin{tabular}{l|c} 
Fuel type & Energy density MJ/kg \\
\hline Wind & 0.00006 \\
\hline Battery & 0.001 \\
\hline Hydro & 0.72 \\
\hline TNT & 4.6 \\
\hline Wood & 5.0 \\
\hline Petrol & 50 \\
\hline Hydrogen & 143 \\
\hline Nuclear fission & 88250000 \\
\hline Nuclear fusion & 645000000 \\
\hline
\end{tabular}

as exemplified by the Spanish solar photovoltaic system described earlier. It is this very large ratio that shows that renewable energy will provide order $10-20 \%$ of global energy in optimistic terms in 2035 (as per Fig. 1), and there is no prospect of seriously reducing fossil fuel emissions without an accompanying fall in global standards of living directly implied by large reductions in per capita energy use.

\section{Retrofitting buildings—a large civil engineering project}

About a third of all energy consumed in the world is spent on heating or cooling air and water in buildings. In the UK, there are $22 \mathrm{M}$ houses and 5.5M nondomestic buildings. Furthermore, for every ten new homes built, only one is demolished. Of the present building stock, $87 \%$ will still be present in 2050 , forming over $70 \%$ of the then stock, so that new buildings alone will not make deep inroads into total $\mathrm{CO}_{2}$ emissions from the building stock: we must retrofit ${ }^{28}$ on a national scale. One knows that $\$ 10 \mathrm{~K}$ spent on improving the thermal fabric of the building shell of a house and the energy efficiency of the appliances therein will have little impact on the net energy use and emissions of $\mathrm{CO}_{2}$. By contrast $\$ 1 \mathrm{M}$ would be enough to rebuild to a stateof-the-art specification. $\$ 100 \mathrm{~K}$ per house will enable significant measures to be undertaken, aiming to halve the $\mathrm{CO}_{2}$ emissions. When factoring in the nondomestic buildings, the cost to the nation of halving the $45 \%$ of UK energy used in buildings, and so reducing the $\mathrm{CO}_{2}$ emissions by $23 \%$, is approximately $\$ 3 \mathrm{~T}$. If this was to be done over 40 years, we would need a trebling of the building workforce and of the throughput of the building materials supply chain. The workforce on this project would represent over $1.5 \%$ of the total population or $3 \%$ of the total workforce. The embodied $\mathrm{CO}_{2}$ emissions in the transformation would take about 30 years to payback. The payback in terms of reduced energy bills is longer at approximately 50 years (far too long for conventional financial instruments). This project consumes about $2 \%$ of the UK GDP over 40 years. With the fabric of a large number of buildings protected because of their heritage status, some parts of the UK, e.g., the South West, would have to have all other buildings upgraded to zero emission standards for that region to contribute its full share of the $80 \%$ reduction of emissions from the sector. As a civil engineering project in isolation, the deep retrofitting of existing buildings does not make economic or ecological sense. ${ }^{29}$

One third of the domestic buildings in the UK were built in (i) Victorian times and in (ii) the postwar period to 1965: first coal, and then oil, were cheap fuels and a robust thermal envelope for a building was not a design priority, in contrast with a similar building in Spain or Sweden where keeping heat in or out of parts of the year is a high priority. If the UK were typical, the global retrofit project is of order $\$ 600 \mathrm{~T}$, which dwarfs sums normally spoken of in international finance.

\section{Summary}

The scale of the different specific engineering challenges of the decarbonization project is without precedent in human history. This means that any new technology introductions need to 
be able to meet the huge implied capabilities. An appreciation of this sheer scale is very rarely admitted or even appreciated in many of the reports that advocate global decarbonization.

\section{Generic lessons learned from introducing new technologies applied to decarbonization}

The first oil price shocks in the 1970s were the trigger for the start of intensive R\&D associated with what are today's 1st generation renewables: solar, wind, tidal, and wave power, together with the range of cultivated biofuels from grasses to algae. Together they produce less than $1 \%$ of the world's energy, and we are now halfway between the 1970s and 2050s by which time the $\mathbf{8 0 \%}$ decarbonization project is supposed to be completed. ${ }^{18}$ In my opinion, any project management auditor would say we are well behind our schedule. In this section, I focus on the specific lessons from the recent history of technology change and reflect on them in the context of the global decarbonization project.

\section{Successful new technologies improve the lot of mankind}

I have already referred to the use of Watt's steam energy as a source of energy to improve harvesting, greatly aiding agricultural productivity. Notice too that the windmills of Europe stopped turning: the new source of energy was compact, moveable, reliable, available when needed, and of relatively low maintenance. This differential has widened ever since, and the recent windmills do not greatly close the gap in practical utility or cost. Later in the 19th century, electricity from steam turbines became available to lighten the darkness, power an increasing range of machinery, and increase the productivity of mankind to the extent that can be seen today when one contrasts an industrial city with a remote off-grid rural community. It is this energy which has underpinned the ability to improve sanitation, transport goods, and allow modern communications and advanced healthcare. During the 20th century, jet engines greatly reduced the time taken to get between two distant places, with semiconductor technologies eliminating that time with virtual presence anywhere anytime. The genetic engineering technologies have greatly speeded up the processes of plant breeding and the recent green revolution means that the larger population of the world now is better fed than ever before. The remaining areas of starvation are universally associated with war, and/or bad governance interfering with supply chains.

There is more in the pipeline with artificial meat having been demonstrated in the laboratory. ${ }^{30}$ One can envisage large cities being self-sufficient in animal protein within their city limits on the timescale of 40 years: there do remain problems of practical scale-up to be able to make tens of tons of such protein on a daily basis. In medicine, the use of antibiotics has caused a major reduction in infections, although the overuse has given rise to antibiotic-resistant germs, so that the warfare with germs may need another round to keep infection under control. The smart phone today, which fits in the palm of one's hand, performs the functions of what were twenty or more separate and bulky items only twenty years ago-one could cover a tabletop with them: camera, radio, telephone, answer-machine, torch, photoalbum, dicta-phone, music centre, satellite navigation system, video recorder and player, compass, stop-watch, Filofax, diary, and many more. This is a classic example of business as usual dematerializing modern living, and using less energy (yet to be systematically quantified) as a direct consequence. Most of these older items will not be replaced. Furthermore farmers in India and Africa use their phones to decide when to go to market to get the best price for all they bring-they need no longer to overgrow to compensate for coming too soon or too late to market. ${ }^{9}$ The notion of many integrated sensor networks enabling more efficient living in future cities is already being introduced, and is set to become pervasive in the next $20-30$ years. Autonomous vehicles, real-time health monitoring and diagnosis, and energy load balancing of demand at the urban scale are just three of many benefits that are anticipated. To the extent that these networks have low power consumption, for which the components are being developed, this will represent a reduction in the demand of personal mobility and the consequent use of energy. 3D printing is set to reduce manufacturing waste, and the increasing trend of manufacture for end-of-life recycling is likely to reduce the demand on new resources and enhance the sustainability of production.

Successful new technologies have improved the lot of mankind. They represent the exploitation of new ideas in science. Liquid crystals, once developed to operate at room temperature, first made portable electronics possible with a low power display, and it was a further 30 years before the original goal of a flat-screen television for small rooms in Japanese homes came to the market. The mobile phone was developed for talking, but texting and data transfer were rapidly achieved as unintended bonuses.

What about failed technologies? Not every technology introduction has succeeded. ${ }^{31}$ Just one that recurs regularly in modern times is caused by software failures: in the UK, we have the London Ambulance service, the electronic London Stock Exchange, electronic patient records in the National Health Service, and the project to put tax and benefit records and payments on line. These failures have cost tens of billions of pounds, and have a common theme that those designing the systems did not consult with those having to make the proposed service work, and even where they did, the intermediate contract negotiations changed specifications and costings without consultation. ${ }^{32}$ Another whole class of failures is where public expectations or aspirations where not met, i.e., new technologies that went against the grain. Home working has not evolved to the extent or the way anticipated, and some of the predictions around the use of artificial intelligence were overblown and the required infrastructure was never put in place. Many modern database entry systems with pull down menus prevent the reporting of exceptional events, information of which is often as important as the aggregation of data on the common events.

As we decarbonize the world, we must improve the lot of humanity, not degrade it, and we must go with the flow of human progress not across or against it. Failure to appreciate these lessons could result in major investments not realizing their goals, 
with much of the investment having to be written off, representing lost opportunities to have done something else that was more effective.

\section{R\&D in new technologies is a good use of public money}

Really new technologies often span several existing sectors of private industry which would benefit or lose out if the new technology were introduced: coachmen in the age of buses and trains, pigeon carriers in the age of telegraph. It is difficult to have foreseen the rise of electronics to its current pervasive state if governments around the world had not supported relevant $R \& D$ in the early stages. Today the global R\&D budget exceeds $\$ 1 \mathrm{~T}$, and the public purse contributes much of that. ${ }^{33}$ In many advanced countries, there is significant public support of private $R \& D$ in the perceived total public interest, an interest that is not the particular focus of any one company in the private sector. The analysis of the origin of Apple's technologies is an exemplary case of the private capture of public investment. ${ }^{34}$ In the last 40 years, there has continued to be public-good R\&D undertaken in many countries on new energy technologies that have given rise to the first generation of renewables. The support goes well down the development channel as well as the background research. This is because the private risk of initial small scale deployment to test the effectiveness of a new technology is often too high for a single company or consortium to bear. The USA has the most effective ecosystem of innovation in the world, eclipsed only for a brief period in the 1980s by Japan. The role of mission agencies is vital here: whereas in Europe, there is public funding in the form of grants to companies for development activities, the agencies go one very important step further, namely to identify an end-user of the outputs of any piece of work which must be in the form of a prototype product or service. Whereas the output of such work is a report on the shelf of a bureaucrat in the EU, a satisfied customer with future plans is the output in the US system. ${ }^{35}$ However, any future analysis of the recent renewable energy bankruptcies (as discussed below) should examine the earlier parts of the supply chain of new ideas and see whether some of the development programmes had been funded without adequately hardnosed assessment of the economic and social issues associated with the future small and then large scale deployment.

\section{Premature roll-out of immature/uneconomic technologies is a recipe for failure}

The virtuous role of government funding in R\&D is to be contrast with the litany of failure in recent times of subsidies in support of the premature rollout of technologies that are uneconomic and/or immature.

In the late $1980 \mathrm{~s}$, large scale installations were made in the Mojave desert of farms of windmills and solar panels. One can see the square kilometers of green industrial dereliction by googling the phrases 'abandoned wind farm' and 'abandoned solar farm', respectively. The useful energy generated within these farms was insufficient to pay the interest on capital and to maintain production. The companies have gone bankrupt, and there is no one to decommission the infrastructure and return the sites to their pristine condition. I note that the remains are there to be mocked as an infrastructure project has gone wrong, and they will remain for decades, a modern version of the hubris of Ozymandias or the builders of the Tower of Babel. It is important to note that some (but not all ${ }^{36}$ ) second and third generation wind and solar farms in the Mojave desert have fared and are faring better, ${ }^{37}$ but the lesson here remains that premature roll-out of unready technology is unwise.

In normal areas of hot new technology, such as cars, aeroplanes, and integrated circuits in the past, there were many small players in at the start but as the industry matured there was a major consolidation until a few very large players remain. We might expect that in the renewable energy sector, but the long-term winners are not yet clear.

The primary problem is the use of public money, i.e., subsidies, to encourage the roll-out. They have a plethora of unintended consequences in the energy infrastructure sector. During the economic crisis of 2008/9 many of the subsidies were reduced or withdrawn in the USA. Many small companies went bankrupt. This has continued with subsidy reductions in the UK, Germany, Spain and elsewhere with further bankruptcies in the alternative energy sector. ${ }^{38}$ Indeed there is an index for the stock value of alternative energy companies, RENIXX, that lost $80 \%$ of its value between 2008 and 2013, although it has recovered a little of that fall more recently. It is certainly not the place for pension fund investments: if the market were mature and stable, a 40-year programme to renew the global energy infrastructure should be the place for pension funds. ${ }^{39}$ The reason so far for these failures is that the technologies are uneconomic over their lifecycles and immature in terms of the energy return on their investment (as in section "Energy return on investment (EROI)" above). In China, public subsidies continue with solar panels being sold at about a $30 \%$ loss on the cost of production. ${ }^{40}$ That is a political strategy at work rather than an industrial strategy. In democracies, there is unlikely to be multiparty, multigovernment consensus lasting for the multidecadal timescales implied by major infrastructure change.

There is an unintended and unwanted social consequence of the roll out of these new technologies. There is ample evidence in the UK of increasing fuel poverty (i.e., household spending over $10 \%$ of disposable income keeping warm in winter) in the regions of wind farm deployment where higher electricity bills are needed to cover the rent of the land (from usually already rich) landowners, a direct reversal of the process whereby cheap energy over the last century has lifted a significant fraction of the world's poor from their poverty. ${ }^{41}$ Renewable energy supplements are viewed as socially divisive.

The issue of electric cars provides another area of concern about moving too fast. The batteries for these cars are very bulky, and in the quest for ever increasing energy density, materials of greater intrinsic instability are used: electrodes swell and shrink during charge and discharge, each time weakening the overall structure. The materials tend to be rich in oxygen, and any small rupture in an internal membrane caused by a minor impact can lead to short-circuits through flammable 
electrolytes which over time can erupt as a fiercely burning fire, an intolerable side effect. ${ }^{42}$

\section{Technology breakthroughs are not pre-programmable}

When public commentators such as Thomas L Friedman enter the debate about energy technologies, they urge more research to produce a breakthrough energy technology, in his case, a 'plentiful supply of clean green cheap electrons'. ${ }^{43}$ It is salutary to realize that all but two of the energy technologies used today have counterparts in biblical times, the only newcomers being nuclear energy and solar photovoltaics. The delivery of coal, gas, wind, water, and solar energy may be quite different today from then but the underlying principles of operation have not changed. Since nuclear fusion was first demonstrated, there has been a 60 -year effort to tame it for a source of electrical energy, but so far without success. One can ask the experts whether they might have made more progress with more money, but the challenges have remained profound. Even if there were a breakthrough tomorrow in the basic processes, it would still take of order 40 years (rather than 20 in my opinion) to complete the further engineering and technology work and deploy fusion reactions to be able to provide (say) $10 \%$ of the world's electricity. We must get to 2050 without it.

We are used in the IT sector to foresight programmes, which are possible on the basis of Moore's law of exponentially growing transistor count on chips continuing to hold, allowing one to predict future products. ${ }^{44}$ It is one thing to predict the progress of a known technology (as it is with first generation renewables), it quite another to predict the arrival of a qualitatively new technology. At present we power the world with fossil fuel, nuclear power, and some hydro and geothermal power, and of those only the first two have the total capacity potential to provide the scale of energy needed for 9B people on earth in 2050 , especially when more than half of these are living in megacities (see section "Tackle megacities first" below).

\section{An untrusting population will not engage}

There is an important point which confronts all technology introductions, namely social acceptability. I am not sure how global is the pattern of behaviour that is common in the UK, namely the widespread distrust of people who come to the door offering something free or heavily subsidized: too often it is too good to be true. In recent years, offers of free or subsidized loft insulation for homes have been made to help reduce energy bills, but with poor take-up ( $<10 \%$ locally). In addition to concerns about the hassle factor, the main problem is the lack of a court-tested guarantee lasting 25 years that the contractor will put right any adverse consequences, unintended or not, at their own expense. So far 'saving the planet', or even more parochially, saving on energy bills, is not enough to overcome the hassle factor and the distrust. ${ }^{45}$

\section{Finance is limited, so actions at scale must be prioritized}

The sum involved in renewing the energy infrastructure in the UK is about $£ 200 \mathrm{~B}$ over the next decade. ${ }^{46}$ A large element of this cost is to make good the lack of infrastructure investment over the last 20 years since a privatized energy market was introduced. In addition the large scale modification of the grid to cope with multiple renewable energy inputs has to be included. There remains a dispute in the public domain as to where these costs lie. The grid as we know it in major industrial countries has evolved over a period of 100 years on the basis of a relatively few large sources of energy connected to the grid which circulates power to substations from which it is transmitted to individual end-users in a broadcast mode. With multiple small and independent sources of energy from wind and solar installations, the grid topology has to change to cope with this very different quality of energy. The conventional suppliers of energy say that they should not have to cover these extra costs which should be book-kept with the renewable energies in the overall balance sheet of costs. A similar book-keeping problem arises with the costs of back-up to intermittent renewable energies. The combined cycle gas turbine generators that have delivered base load electricity to the grid in Germany are now being asked to act in back-up mode, with frequent acceleration and deceleration of the turbines, for which purpose they were not designed and they shorten the in-service life time as a result. ${ }^{47}$ The cost analyses of future energy are bedevilled by the assignments of additional consequential costs. In practice as consumers, we buy the energy provided by electricity, blind to the particular way it is produced.

The scale of the costs of these energy bills is such that one cannot make mistakes in infrastructure investment decisions. A wrong investment is a missed opportunity on a large scale.

Finally, it is as well to remember that there are only ever two sources of payment, the consumer and the taxpayer, and the only issue at stake between them is the directness with which costs are recovered. ${ }^{48}$

\section{Some general issues}

Before charting the appropriate way forward, there are some other relevant and general issues that go beyond narrow technology development that need to be discussed.

\section{If the climate imperative weakens, so does the decarbonization imperative}

The climate models have now been shown conclusively to be continuing to overheat the earth as 17 years of real world data now show no increase in the globally averaged surface temperature, the original talisman of global warming. The comment that many of the warmest years in the directly recorded history have been in the last decade is not inconsistent with the observed hiatus. If that hiatus in temperature should continue until the next IPCC assessment in 2021, any scientist respecting the canons of Newton, Rutherford or Einstein would expect to see a further significant further reduction of the predictions of dangerous future climates. In my view, the 2014 IPCC report was somewhat obfuscatory on this issue: there was no expert assessment of one key parameter, ${ }^{16}$ the climate sensitivity (the expected actual temperature rise for a doubling of $\mathrm{CO}_{2}$ in the atmosphere), because of wide disagreements between models and 
data, and the current debate points to a lowering of the estimated range of values. ${ }^{49}$ In addition any prospect of a further reduction of the temperature rise over the next few decades (e.g., from the sun ${ }^{50,51}$ ) gives us extra breathing space on new technology introductions. This weakening of the timescale for future temperature rises has a direct policy implication in the here and now. Since the design lifetime of most fossil fuel plants is of order 40 years, the world would be wise to opt for another generation of fossil fuels to continue the improvement of the lot of mankind, while making a more determined effort over a longer time to develop real workarounds to the currently perceived problem of carbon dioxide emissions. It is clear to me that every further step along the current pathway of deploying first generation renewable energy is locking in immature and uneconomic systems at net loss to the world standard of living. In view of the level of hard engineering evidence for this point that is already available, the romantic notion of sustainability at any cost, as opposed to hard-nosed sustainability, is indefensible. There should be a calling to account on how these matters came about. Also, by 2050 a whole new demography future will be upon us (see section "The demographic transition" below).

\section{Tackle megacities first}

If one were to regard the decarbonization of the global economy as a great battle to avert an impending disaster, a sensible strategy would be to tackle the largest component of the problem first. In recent years, more people have started to live in cities than in the countryside. By 2050 , well over half the global population will live in megacities with multimillion populations. How will megacities be energized? Consider Shanghai today, a city of $22 \mathrm{M}$ people covering an area of $6000 \mathrm{~km}^{2}$. We would need about four times that area to produce the electricity by wind or biomass technology using international average uptimes and 24/7 supply. But this is where the major source of food for Shanghai is grown. ${ }^{52}$ One needs a dense source of local energy to avoid energy losses in transmission. The problem for Hong Kong with 7M in $1000 \mathrm{~km}^{2}$ is even more acute. Solar at present without large-scale storage could only provide about $5 \%$ of the electricity needs averaged over a year (by comparison with German data) and require city scale areas. ${ }^{51}$ Only nuclear energy and fossil fuels are available now and only some form of carbon capture and sequestration might make any difference to carbon emissions by 2050 for megacities. Once exceptions in the decarbonization project are made for megacities, the integrity of the debate on decarbonization is lost. The provision of current generation renewables is suited to remote areas of low density and off-grid. What applies to Phoenix (Arizona, USA) as a very-low-population density 'Sun City' does not apply to megacities. The present renewable energy sources cannot empower most of the world's large city population now, and will provide for a smaller fraction of the megacity population in 2050 . The initial schemes of large-scale projects such as Desertec have been abandoned by investors not convinced by the returns or the required decades of political stability needed to secure those returns.

\section{The demographic transition}

The population of the world started growing sharply at the time of the industrial revolution. Improved diet, sanitation and clean water access reduced infant mortality. In the 1960s, a qualitatively new feature emerged which will come to dominate demographics in the latter part of last century: the rate of growth of the population started to decline. As of now wherever the majority of people live in urban areas and have access to universal primary education (particularly for girls) the indigenous populations, i.e., independent of immigration, are in absolute decline. ${ }^{53}$ This applies now in Europe, North America, and Japan. The drop in the fertility rates for child-bearing women in Europe (who are educated and emancipated so as to be able to choose) is now so severe that Italy's population will shrink from $61 \mathrm{M}$ to $8 \mathrm{M}$ and Germany from $80 \mathrm{M}$ to $4 \mathrm{M}$ over the century. ${ }^{53}$ The population is predicted to grow to $9 \mathrm{~B}$ by mid-century and to fall back, even to $7 \mathrm{~B}$ by $2100 .{ }^{54}$ In one hundred years, the discourse will be on the possible uses of infrastructure for $2 \mathrm{~B}$ people no longer alive on the earth. This future can be seen in certain parts of the world where depopulation has already started, as in the east of the former East Germany. Villages are vacated, buildings torn down-if left to decay they collect vermin and detract from the quality of life of the few who remain. This is now a more certain future than possible uncontrolled future climates.

This prospect has a major impact on the contemporary response to the perceived threats of future climate change. The infrastructure being planned now has to last only 100 years and should be designed for dismantling at the end of service life. The increased energy intensity of industry coupled with an eventually declining population is not as yet factored into the climate models.

\section{The integrity of policy advice}

Political structures in western democracies are used to lobbying. Groups with a common interest urge particular actions on governments by emphasizing the upsides of a particular action and the downsides of not doing that action. This partial approach is quite inadequate when giving advice (as opposed to advocacy) on a particular topic. Here, four scenarios have to be laid out with something like equal measure: describing the issue at hand followed by both the upsides and downsides of both doing nothing and doing something in particular. This is put in front of elected representatives for them to make the decision.

As mentioned in the introduction, the academies worldwide have come off the fence on these matters. If one examines the most recent joint report of the US National Academy of Sciences and the UK Royal Society on the Science of Climate Change, ${ }^{11}$ the answer to question 17 is revealing. To the question whether a few degrees of warming really matters, the answer is 220 words of dire warning concluding with the following 19 words: 'Even though certain regions may realize some local benefit from the warming, the long-term consequences overall will be disruptive'. While this almost certainly represents the balance of the research actually done, i.e., to find every possible trouble 
wherever it might be, it does point up the glaring absence of any substantial work on the upsides of increased carbon dioxide emissions today, which include over $10 \%$ of the increased global agricultural productivity, ${ }^{55}$ and the greening of the deserts and the tropics more generally. 56

In 2011, 43 Fellows of the Royal Society petitioned the Council of the Royal Society to revise its public position on Climate Change from one that violated its motto (Nullius In Verba-take no-ones work for it but check the facts yourself) in pointing out that anyone who disagreed with the IPCG view was mistaken, to one that properly emphasized the uncertainties, which grew greater the further one looked ahead. ${ }^{57}$ Indeed it is only in July 2014-20 years too late for me-that a two-sided debate on what to do about anthropogenic climate change was held at the Royal Society, ${ }^{58}$ although not under the auspices of the Royal Society,-that is yet to happen.

\section{The ecological downsides of first generation renewable energies}

In pointing to the well-known deleterious aspects of the fossil fuel industry, those who ask for a decarbonization policy are remarkably silent on the downsides of the renewable energy sources that they would have in its place. No form of energy is without its downsides. When exceptions to draconian legislation that protects native wildlife, like the golden eagle, the national symbol of the USA, are made for concentrated solar farms and windmills, there is an unfortunate asymmetry in practice. ${ }^{59}$ If there was a bounty on each animal that returned to the preservation of such animals, factored directly into the cost of these renewables, there would be some sense of justice. In the UK, the objections to fracking are based on much higher standards of environmental regulation than that have been applied to wind and solar projects and even projects such as the Severn Barrier to the Cardiff Bay Tidal Energy Lagoon place relatively little weight on the destruction of habitats for both fish and birds.

The materials requirements for solar, wind, and wave power are very high, scaling with the large areas needed to generate GW of electricity, compared with the more materials demands for fossil fuel energy generation at the same scale. We do not have a good visibility of the costs of recycling wind turbines or solar panel arrays, but this does not stop those who would emphasize the costs of decommissioning nuclear power stations. Again the costs of the former reflect the very large areas that their elements occupy, and the total masses involved. The early abandoned energy projects in the Mojave desert are at least as intolerable as those of the rust belt of conventional industry in the Eastern States. Postbankruptcy clean-up and remediation is on a larger scale than for conventional power plants where the areal dimensions are much smaller. The materials for large-scale batteries provide other challenges as described above in section "Premature roll-out of immature/uneconomic technologies is a recipe for failure".

\section{Other challenges facing the planet}

I have used the focus on climate change to frame this review. The millennium development goals represent the only example to date where global problems have been tackled on a global scale: some have been achieved while others have not. ${ }^{60}$ There are other challenges facing the world, some of greater likelihood and greater impact than the future climate disruption. The combination of technical advances across many disciplines and the demographic transition will probably avert the worst in terms of resource demands and energy supply for the next century. There is the possibility of a new pandemic where the virulence and transmissivity of pathogens work together rather than against each other to overcome the protection provided by modern medicine. The behaviour of the sun over the last 30 years is a repeat of that before the world entered the last little ice age. ${ }^{61}$ If we had to feed $9 \mathrm{~B}$ rather than $1 \mathrm{~B}$ last time (in the middle of the little ice age), then every tonne of $\mathrm{CO}_{2}$ in the atmosphere will be a help in 2050! A mega-volcanic eruption, a meteor strike or a solar electromagnetic storm could serious impact society's infrastructure (the last crippling much electronics).

The disruption to the society of New Orleans from Katrina's wind damage gave a clear picture of the deep reliance of modern society on electricity-if no commerce is possible through the unavailability of instant credit, society can breakdown very quickly. Some in the UK can recall miners' strikes in the 1970 s that lead to widespread, but temporary, electricity blackouts. Discretionary spending on improving the resilience of today's energy infrastructure would get the popular vote over spending to avert possible long-term climate change.

Air pollution is a real and present problem, one that fossil fuels contribute to especially in developing countries where small and low quality coal fired power plants support businesses in the suburban areas of large cities such as Beijing. Older transport vehicles in congested inner city roads exacerbate the problem. On the evidence of London, Los Angeles and other cities in developed countries, the problem is soluble if the local economy is dynamic, as codes for vehicle performance are tightened, and small energy plants are closed and replaced by larger and more modern plants. This trend will apply over the next decades in the Brazil, Russia, India, China (BRIC) countries as new infrastructure supports the rising middle class described in Fig. 1.

\section{The way forward}

It is surely time to review the current direction of the decarbonization project which can be assumed to start in about 1990, the reference point from which carbon dioxide emission reductions are measured. No serious inroads have been made into the lion's share of energy that is fossil fuel based. Some moves represent total madness. The closure of all but one of the aluminium smelters that used gas-fired electricity in the UK (because of rising electricity costs from the green tariffs that are over and above any global background fossil fuel energy costs) reduces our nation's carbon dioxide emissions. ${ }^{62}$ However, the aluminium is now imported from China where it is made with more primitive coal-based sources of energy, making the global problem of emissions worse! While the UK prides itself in reducing indigenous carbon dioxide emissions by $20 \%$ since 1990 , the attribution of carbon emissions by end use shows a $20 \%$ increase over the same period. ${ }^{63}$ 
It is also clear that we must de-risk all energy infrastructure projects over the next two decades. While the level of uncertainty remains high, the 'insurance policy' justification of urgent largescale intervention is untenable, and we do not pay premiums if we would go bankrupt as a consequence. Certain things we do not insure against, such as a potential future mega-tsunami, ${ }^{64}$ or a supervolcano, ${ }^{65}$ or indeed a meteor strike, even though there have been over 20 of these since 2000 with the local power of the Hiroshima bomb! ${ }^{66}$ Using a significant fraction of the global GDP to possibly capture the benefits of a possibly less troublesome future climate leaves more urgent actions not undertaken.

Two important points remain. The first is that there is no alternative to business as usual carrying on, with one caveat expressed in the following paragraph. Since energy use has a cost, it is normal business practice to minimize energy use, by increasing energy efficiency (see especially the recent improvement in automobile performance), ${ }^{67}$ using less resource material and more effective recycling. These drivers have become more intense in recent years, but they were always there for a business trying to remain competitive.

The second is that, over the next two decades, the single place where the greatest impact on carbon dioxide emissions can be achieved is in the area of personal behaviour. Its potential dwarfs that of new technology interventions. Within the EU over the last 40 years there has been a notable change in public attitudes and behaviour in such diverse arenas as drinking and driving, smoking in public confined spaces, and driving without a seatbelt. If society's attitude to the profligate consumption of any materials and resources including any forms of fuel and electricity was to regard this as deeply antisocial, it has been estimated we could live something like our present standard of living on half the energy consumption we use today in the developed world. ${ }^{68}$ This would mean fewer miles travelled, fewer material possessions, shorter supply chains, and less use of the internet. While there is no public appetite to follow this path, the short term technology fix path is no panacea.

\section{Conclusions}

Over the last 200 years, fossil fuels have provided the route out of grinding poverty for many people in the world (but still less than half of all people) and Fig. 1 shows that this trend is certain to continue for at least the next 20 years based on the technologies of scale that are available today. A rapid decarbonization is simply impossible over the next 20 years unless the trend of a growing number who succeed to improve their lot is stalled by rich and middle class people downgrading their own standard of living. The current backlash against subsidies for renewable energy systems in the UK, EU and USA is a sign that all is not well with current renewable energy systems in meeting the aspirations of humanity.

Finally, humanity is owed a serious investigation of how we have gone so far with the decarbonization project without a serious challenge in terms of engineering reality. Have the engineers been supine and lacking in courage to challenge the orthodoxy? Or have their warnings been too gentle and dismissed or not heard? Science and politicians can take too much comfort from undoubted engineering successes over the last 200 years. When the sums at stake are on the scale of $1-10 \%$ of the world's GDP, this is a serious business.

\section{Postscript: renewable energy in Germany}

The actual data for electricity in Germany during 2014 is now available, ${ }^{51}$ the fruits of a $\$ 200 \mathrm{~B}$ investment in wind and solar energy. While one can show isolated times of a few hours on one or two days where significant (say $>30 \%$ ) electricity is generated by renewable sources (see slides 266-9 of Ref. 51), the total contribution each of wind and solar sources of electricity average to $\mathbf{8 \%}$ of average demand, leaving fossil fuels and nuclear energy to provide the other $84 \%$ (see slides $11-13$ of Ref. 51). The problem is that for significant periods during winter when there is no solar or wind energy, the entire peak annual demand must be provided from the older generators. Not a single old generator can be turned off because it is needed to cover intermittency. However the older generators are providing $84 \%$ not $100 \%$ of the energy as they used to, and they must now charge a higher price to cover the same depreciation and finance costs. In some cases it is worse than this: many for the gas turbines were designed for base load operation, and when used in load balancing mode, the constant acceleration and deceleration of the shaft shortens its life to an unacceptable degree. The owners are mothballing their assets for future base load operation rather than misuse them. The cost of electricity for Germany users is higher than elsewhere. Note that a doubled penetration of wind and solar will double these cost problems without any compensating relief.

\section{NOTES AND REFERENCES:}

1. Malthus T.R.: An Essay on the Principle of Population, (1798), Gilbert G. ed.; Oxford Paperbacks Oxford World's Classics: Oxford, UK, 2008, 208 pages.

2. Mayhew R.J.: Malthus: The Life and Legacies of an Untimely Prophet (Harvard University Press, Cambridge, UK, 2014).

3. Selections from the Edinburgh Review Comprising the Best Articles Form that Journal, from its Commencement to the Present Time with a Preliminary Dissertation and Explanatory Notes, Cross M. ed., Vol. III (of VI); Baudry's European Library: Paris (1835); p. 133.

4. Stanley Jevons W., The Coal Question, 2nd ed. (Macmillan and Co., London, UK, 1866).

5. Meadows D.H., Meadows D.L., Randers J., and Behrens Ill W.W.: Limits to Growth: A Report for the Club of Rome's Project on the Predicament of Mankind (New American Library, New York, 1977), paperback, ISBN 0-451-13695-0; Universe Books, New York (1972), ISBN 0-87663-222-3.

6. Murray J. and King D.: Oil's tipping point has passed. Nature 481, 433-435 (2012).

7. Lomborg B.: The Sceptical Environmentalist (Cambridge University Press, Cambridge, UK, 2001), Fig. 62.

8. Hansen J., Kharecha P., and Sato M.: Climate forcing growth rates: Doubling down on our Faustian bargain. Environ. Res. Lett. 8, 011006 (9pp) (2013).

9. Kelly M.J.: Why a collapse of global civilization will be avoided: A comment on Ehrlich and Ehrlich. Proc. R. Soc. B 280, 20131193 (2013).

10. Note the number of distinguished Fellows of the Royal Society associated with the Global Warming Policy Foundation, led by Lord Lawson, with whom the then President of the Royal Society has had a public spat. See http://www.thegwpf.com/lord-lawsons-letter-sir-paul-nurse/. (accessed November 10, 2015).

11. Montford A.: Nullius in verba: On the Word of No One: The Royal Society and Climate Change (The Global Warming Policy Foundation, 
GWPF Report, 2012), p. 6, http://www.thegwpf.org/images/stories/ gwpf-reports/montford-royal_society.pdf. (accessed November 10, 2015).

12. The National Academy of Sciences and The Royal Society: Climate Change: Evidence \& Causes: An overview from the Royal Society and the US National Academy of Sciences (Royal Society and the US National Academy of Sciences, 2014), https://royalsociety.org/ / media/Royal_Society_Content/policy/projects/climate-evidencecauses/climate-change-evidence-causes.pdf. (accessed November 10 , 2015).

13. Funtowicz S.O. and Ravetz J.R.: A New Scientific Methodology for Global Environmental Issues. In Ecological Economics: The Science and Management of Sustainability, Costanza R. ed.; Columbia University Press: New York, 1991; pp. 137-152.

14. Royal Commission on Environmental Pollution: Energy-The Changing Climate, Twenty-second Report (2000). http://webarchive.nationalarchives. gov.uk/20110322143804/http://www.rcep.org.uk/reports/22-energy/22energyreport.pdf.

15. The United Kingdom Committee on Climate Change: http://www.theccc. org.uk/.

16. The Intergovernmental Panel on Climate Change: Fifth Assessment Report (AR5) (2013). http://www.ipcc.ch/report/ar5/index.shtml.

17. Allitt P.: A Climate of Crisis: America in the Age of Environmentalism (Penguin, New York, 2014).

18. International Energy Agency: World Energy Outlook (2013). http://www. worldenergyoutlook.org/publications/weo-2013/\#d.en.36200.

19. Data from page 42 of the BP Statistical Review of World Energy (2014). http://www.bp.com/content/dam/bp-country/de_de/PDFs/brochures/ BP-statistical-review-of-world-energy-2014-full-report.pdf.

20. MacKay D.J.C.: Sustainable Energy: Without the Hot Air (UIT Cambridge Ltd, 2009). Available from: http://www.withouthotair.com. (accessed November 10, 2015).

21. The BP Energy Outlook (2015). http://www.bp.com/content/dam/bp/ pdf/energy-economics/energy-outlook-2015/bp-energy-outlook-2035booklet.pdf, Slide 12(b). (accessed November 10, 2015).

22. Ernst and Young: Hitting the Sweet Spot: The Growth of the Middle Class in Emerging Markets (2013). http://www.ey.com/Publication/vwLUAssets/ Hitting_the_sweet_spot/\$FILE/Hitting_the_sweet_spot.pdf and H. Kharas and G. Gertz: The New Global Middle Class: A Cross-Over from West to East (Wolfensohn Center for Development at The Brookings Institute, http://www.brookings.edu/ /media/research/files/papers/2010/3/ china-middle-class-kharas/03_china_middle_class_kharas.pdf. (accessed November 10, 2015).

23. Weißbach D., Ruprech G., Huke A., Czerski K., Gottlieb S., and Hussein A.: Energy intensities, EROIs (energy returned on invested), and energy payback times of electricity generating power plants. Energy 52, 210-221 (2013). (accessed November 10, 2015).

24. Prieto P.A. and Hall C.A.S.: Spain's Photovoltaic Revolution: The Energy Return on Investment (Springer, New York, 2013).

25. Fulton M. and Capalino R.: Investing in the Clean Trillion: Closing the Investment Gap: A Ceres Report (2015); pp. 74: http://www.ceres.org/ resources/reports/investing-in-the-clean-trillion-closing-the-cleanenergy-investment-gap/view. (accessed November 10, 2015).

26. Kelly M.J.: Technology introductions in the context of decarbonisation: Lessons from recent history (The Global Warming Policy Foundation, London, 2014). http://www.thegwpf.org/content/uploads/2014/03/ Kelly-lessons.pdf. (accessed November 10, 2015).

27. Fuel density data provided by Professor Douglas Paul, University of Glasgow.

28. Kelly M.J.: Energy efficiency, resilience to future climates and long-term sustainability: The role of the built environment. Philos. Trans. R. Soc., A 368, 1083-10839 (2010).

29. My own detailed study remains unpublished. The typical costs of order $£ 150 \mathrm{~K}$ per household from an exemplar project to retrofit exemplar houses to achieve a $60 \%$ reduction in energy under the UK's 'Retrofit for the Future' programme, (https://retrofit.innovateuk.org/) have been reduced to $£ 50 \mathrm{~K}$ per household on the assumption that benefits of a learning curve will have been captured.
30. Hopkins P.D. and Austin Dacey A.: Vegetarian meat: Could technology save animals and satisfy meat eaters? J. Agr. Environ. Ethics 21, 579-596 (2008).

31. Geels F.W. and Smit W.A., Failed technology futures: Pitfalls and lessons from a historical survey. Futures 32, 867-885 (2000).

32. The Royal Academy of engineering: UK Wasting Billions on IT Projects. http://www.raeng.org.uk/news/news-releases/2004/April/ uk-wasting-billions-on-it-projects. (accessed November 10, 2015).

33. Global scientific collaboration in the 21st century: Knowledge, Networks and Nations, The Royal Society Report (2011) https://royalsociety.org/ topics-policy/projects/knowledge-networks-nations/. (accessed November 10, 2015).

34. Mazzucato M.: The Entrepreneurial State: Debunking Public vs. Private sector myths (Anthem, London, 2013).

35. See the rules for grant applications at http://www.darpa.mil/About.aspx or http://www.sbir.gov/. (accessed November 10, 2015).

36. For details of how insects are attached by the bright lights and birds, including birds of prey follow them into the hot zone, see http:// wattsupwiththat.com/2015/06/15/solar-fossil-fueled-fantasies/. (accessed November 10, 2015).

37. Lists of US solar farms and wind farms and related material can be found at; http://en.wikipedia.org/wiki/Solar_power_plants_in_the_Mojave_ Deserthttp://en.wikipedia.org/wiki/Solar_Energy_Generating_ Systemshttp://en.wikipedia.org/wiki/List_of_wind_farms_in_the_ United_States http://en.wikipedia.org/wiki/List_of_solar_thermal_ power_stations. (accessed November 10, 2015).

38. Nelson T., The green jobs debacle (2012) at, http://tomnelson.blogspot. co.nz/2012/10/the-green-jobs-debacle.html. (accessed November 10, 2015).

39. The renewable energy industrial index: http://www.renewable-energyindustry.com/stocks/. (accessed November 10, 2015).

40. EU finalizes China solar panel subsidy probe: http://www.eubusiness.com/ news-eu/china-solar-energy.qbg. (accessed November 10, 2015).

41. Kelly A.: Climate Policy and the Poor (The Global Warming Policy Foundation, London, 2014). http://www.thegwpf.org/content/ uploads/2014/06/Tony-Kelly.pdf. (accessed November 10, 2015).

42. Google the phrase "immature battery technology" for many reports.

43. Friedman T.L.: Hot Flat and Crowded-Why We Need a Green Revolution and How It can Renew America (Farrar, Straus \& Giroux, New York, 2008).

44. The International Technology Roadmap for Semiconductors, summary of the 2013 report: http://www.itrs2.net/2013-itrs.html.

45. Gifford R.: The dragons of inaction: Psychological barriers that limit climate change mitigation and adaptation. Am. Psychol. 66(4), 290-302 (2011).

46. The UK Office of gas and electricity markets, press release: (2012). https:// www.ofgem.gov.uk/ofgem-publications/76263/20120716riiopressrelease. pdf. (accessed November 10, 2015).

47. Tweed K.: Europe Mothballs 20GW of Gas Plants in 2013, With More to Come (2014). http://www.greentechmedia.com/articles/read/ europe-mothballs-20gw-of-gas-plants-in-2013-with-more-to-come. (accessed November 10, 2015).

48. Helm D.: The Carbon Crunch (Yale University Press, New Haven, 2013).

49. Lewis N.: The implications for climate sensitivity of AR5 forcing and heat uptake estimates. Climate dynamics (May 2105) http://link.springer.com/ article/10.1007/s00382-015-2653-7/fulltext.html. (accessed November 10, 2015).

50. Vahrenholt F. and Luning S.: The Neglected Sun (Stacey International, London, 2013), A translation of 'Die kalte Sonne: warum die Klimakatastrophe nicht stattfindet', (Hoffmann und Campe) (2012).

51. Burger B.: Electricity production from solar and wind in Germany in 2014 (2015) https://www.ise.fraunhofer.de/en/downloads-englisch/pdf-filesenglisch/data-nivc-/electricity-production-from-solar-and-wind-ingermany-2014.pdf/view.

52. Public data and the energy density from Ref. 17.

53. Pearce F.: Peoplequake (Transworld, London, 2011). 
54. Lutz W.: The end of world population growth. Nature 412, 543-545 (2001).

55. Idso C.D.: The Positive Externalities of Carbon Dioxide, http:// www.globalwarming.org/wpcontent/uploads/2013/10/ MonetaryBenefitsofRisingCO2onGlobalFoodProduction.pdf. (accessed November 10, 2015).

56. Donohue R.J., Roderick M.L., McVicar T.R., and Farquhar G.D.: Impact of $\mathrm{CO}_{2}$ fertilization on maximum foliage cover across the globe's warm, arid environments. Geophys. Res. Lett. 40, 3031-3035 (2013).

57. The Royal Society: Climate change: A summary of the science (2010) https://royalsociety.org/topics-policy/publications/2010/climatechange-summary-science/. (accessed November 10, 2015).

58. The Foundation for Science and Technology: Debate Summary: What is the Right Level of Response to Anthropogenic Induced Climate Change? http://www.foundation.org.uk/Events/pdf/20140616_Summary.pdf. (accessed November 10, 2015).

59. Smithsonian SmartNews: How Many Birds so Windmills Actually Kill? http://www.smithsonianmag.com/smart-news/how-many-birdsdo-wind-turbines-really-kill-180948154/. (accessed November 10, 2015).

60. Roston E.: Don't panic: Earth's Nine Threats to Humanity (2011) http:// www.bloomberg.com/slideshow/2011-12-12/don-t-panic-earth-s-ninethreats-to-humanity.html\#slide6.
61. 71 new papers reported in 2013 demonstrating the Sun controls climate, not man-made $\mathrm{CO}_{2}$, see http://bit.ly/1bpzysw and Ref. 50. (accessed November 10, 2015).

62. For the closure of two major aluminium smelters in the UK see http:// en.wikipedia.org/wiki/Anglesey_Aluminium, http://en.wikipedia.org/wiki/ Alcan_Lynemouth_Aluminium_Smelter. (accessed November 10, 2015).

63. Official Report of the UK Department for Energy and Climate Change (2014): 2013 UK Greenhouse Gas Emissions, Provisional Figures and 2012 UK Greenhouse Gas Emissions, Final Figures by Fuel Type and End-User https://www.gov.uk/government/uploads/system/uploads/attachment_ data/file/295968/20140327_2013_UK_Greenhouse_Gas_Emissions_ Provisional_Figures.pdf. (accessed November 10, 2015).

64. For a description of the threats of tsunamis, see http://en.wikipedia.org/ wiki/Megatsunami. (accessed November 10, 2015).

65. For a description of the threats of volcanos, http://en.wikipedia.org/wiki/ Supervolcano. (accessed November 10, 2015).

66. For a description of the threats of meteors, http://en.wikipedia.org/wiki/ Meteoroid\#Meteor. (accessed November 10, 2015).

67. The Environmental and Energy Study Institute's current statement on vehicle efficiency: http://www.eesi.org/topics/vehicle-efficiency/ description. (accessed November 10, 2015).

68. Bajzelj B., Allwood M.J., and Cullen J.M.: Designing climate change mitigation plans that add up. Environ. Sci. Technol. 47, 8062-8069 (2013). 